\title{
A-Z of nutritional supplements: dietary supplements, sports nutrition foods and ergogenic aids for health and performance-Part 30
}

\author{
N M DiMarco, ${ }^{1}$ N P West, ${ }^{2}$ L M Burke, ${ }^{3}$ S J Stear, ${ }^{4}$ L M Castell ${ }^{5}$
}

${ }^{1}$ Institute for Women's Health, Texas Woman's University,

Denton, Texas, USA

${ }^{2}$ Griffith Health Institute,

Griffith University, Southport, Australia

${ }^{3}$ Australian Institute of Sport, Canberra, Australia

${ }^{4}$ Performance Influencers

Limited, London, UK

${ }^{5}$ Green Templeton College,

University of Oxford,

Oxford, UK

\section{Correspondence to}

Linda M Castell, Green

Templeton College,

University of Oxford,

Oxford OX2 6HG, UK:

lindy.castell@gtc.ox.ac.uk

Received 5 January 2012 Accepted 5 January 2012

\section{INTRODUCTORY REMARKS}

Part 30 includes just two supplements: potassium and prebiotics. The role of potassium in exercise metabolism has been well documented in the literature but it seems that its appearance as a component of electrolyte-replacement products is a custom, rather than a necessity, since it is widely found in the diet. By contrast, prebiotics are at the beginning of an investigative story which may conclude by finding some beneficial uses for athletes to promote immune or gastrointestinal (GI) health during times of increased stress.

\section{Potassium \\ Nancy DiMarco}

Potassium $\left(\mathrm{K}^{+}\right)$is the major intracellular cation in the body, with $\sim 98 \%$ of the body potassium stores located inside the cells with a concentration maintained at about $145 \mathrm{mM}$. Its major functions are to promote contractility of cardiac, smooth and skeletal muscle and to influence the regulation of nerve conduction through the influx of sodium $\left(\mathrm{Na}^{+}\right)$and efflux of $\mathrm{K}^{+}$on either side of the nerve terminal, occurring at the rate of $10^{7}$ ions per second. On the surface of a nerve terminal, there are voltage-dependent channels for $\mathrm{K}^{+}$. In humans, at least 15 different $\mathrm{K}^{+}$-specific voltage-dependent channels have been identified. The $\mathrm{Na}^{+} / \mathrm{K}^{+}$ATPase, also known as the Na pump, is the primary active transporter system that maintains the high $\mathrm{K}^{+}$and low $\mathrm{Na}^{+}$intracellular concentrations. The plasma membrane ATPase of all mammalian cells catalyses the reaction: $\mathrm{ATP} \rightarrow \mathrm{ADP}+\mathrm{Pi}$ with obligatory requirements for $\mathrm{Na}^{+}$and $\mathrm{K}^{+}$and $\mathrm{Mg}^{2+}$ required for the dephosphorylation of ATP. Muscle has an especially high activity of this $\mathrm{P}$-type $\mathrm{Na}^{+}$pump which has been estimated to use $60 \%$ to $70 \%$ of the ATP synthesised in nerve and muscle cells. ${ }^{12}$

For active individuals/athletes, sweat is the major route of loss of $\mathrm{K}^{+}$with an average of $5 \mathrm{mEq} / 1$ loss. Early work indicated that the loss of $\mathrm{K}^{+}$from active muscle could contribute to fatigue during prolonged or intense exercise. ${ }^{3}$ Potassium efflux from muscles is greater during high intense/short duration exercise and could result in decreased membrane excitability and cause intracellular acidosis. However, the International Olympic Committee (IOC) Consensus on Nutrition for Athletes ${ }^{5}$ states that there is no convincing justification for the specific addition of electrolytes other than sodium to fluids consumed for postexercise recovery. Indeed, a sports drink containing $25 \mathrm{mM} \mathrm{K}^{+}$and $60 \mathrm{mM} \mathrm{Na}^{+}$did not have an additive effect on restoring hydration over a drink containing $\mathrm{Na}^{+} .{ }^{4}$ In addition, exercise in the heat was not associated with losses of $\mathrm{Ca}^{+}, \mathrm{Mg}^{+}$and $\mathrm{K}^{+}$among tennis players. ${ }^{6}$

Potassium should be consumed as a normal component of the diet rather than as a supplement. Foods containing more than $300 \mathrm{mg} \mathrm{K}{ }^{+}$ serving include banana, potato, orange juice, avocado, lima beans, cantaloupe, peaches, tomato, chicken, salmon, tuna, turkey and unsalted nuts. Some carbohydrate-electrolyte sports drinks provide higher amounts of $\mathrm{K}^{+}(90 \mathrm{mg})$ than others (10-30mg) per $8 \mathrm{fl} \mathrm{oz} \mathrm{(} \mathrm{240ml).} \mathrm{Consuming}$ supplemental forms of $\mathrm{K}^{+}$could result in hyperkalaemia which could lead to cardiac arrhythmias and even cardiac arrest. ${ }^{1}$ The adequate intake (AI) from the diet for adults, age 14 to $>70$ years in the US, is $4.7 \mathrm{~g} / \mathrm{d}$ but the average intake is $\sim 2.5 \mathrm{~g} / \mathrm{d}$. $^{7}$ Individuals with kidney failure or compromised kidney function would need to seek a physician's advice before taking any $\mathrm{K}^{+}$supplement or consuming potassium-rich foods.

\section{Prebiotics \\ NP West}

Prebiotics are non-digestible polysaccharides and other substances that selectively stimulate the growth or activities of one or more species of gut bacteria and which confer a health benefit on the host. ${ }^{8}$ These supplements purportedly yield beneficial health effects via the symbiotic relationship that exists between bacteria inhabiting the GI tract, known as the microbiota and their human host. Prebiotics increase the abundance of bacteria indigenous to the gut by providing nutrients as a source of fuel. Naturally occurring food sources with a prebiotic effect include barley, banana, oats, wheat, soya bean, asparagus, leek, chicory, garlic, artichoke and onion. Resistant starch, found in high amylose maize starch and formed through the heating and cooling of starch foods (rice and pasta), is also receiving growing recognition as a potential prebiotic. Various studies have shown that a prebiotic dose above $2.5 \mathrm{~g}$, which is far higher than that occurring in natural foods, increases the abundance of lactic acid and butyrate-producing bacteria. ${ }^{8}$ However, all prebiotics are not equal, with clinical outcomes being dose-dependent. The most prevalent areas of clinical research with positive outcomes have been with galacto-oligosaccharides (GOS) and fructo-oligosaccharides (FOS). The fermentation of these starches by GI bacteria releases metabolic 
byproducts, including short-chain fatty acids (butyrate, propionate and acetate), vitamins and lipid metabolites. These fermentation byproducts modulate various aspects of the immune system and host metabolism. ${ }^{8}$ Non-digestible polysaccharides are thus an important dietary nutrient that warrants more scrutiny from clinicians and researchers.

The potential benefits of supplementation with prebiotics on athletic performance are most likely indirect: they may be associated with the maintenance of gut health and perhaps a reduced risk of some illnesses which might enhance the athlete's ability to train and compete. Research shows that athletes experiencing higher illness rates over a competition season tend to perform more poorly than their healthier peers. ${ }^{9}$ Preventing illness during training and competition is therefore a high priority for athletes.

Without any direct clinical studies on athletes, select findings from closely related population cohorts provide a glimpse of the potential benefits of prebiotic supplementation in athletes. Prebiotic supplements have had beneficial effects in reducing GI and respiratory illness symptoms. A study examining the effects of 2.5 and $5 \mathrm{~g}$ of GOS supplementation in students $(n=481)$ for 8 weeks around examination time found that stress was positively related to diarrhoea, indigestion, abdominal pain and average daily cold and flu severity scores. Supplementation with GOS was associated with lower GI illness symptom scores while $2.5 \mathrm{~g}$ of GOS was associated with reduced cold and flu severity scores..$^{10}$ Another study of GOS (comprising $48 \%$ of a mixture provided at a dose of $5.5 \mathrm{~g} /$ day) in healthy volunteers undertaking international travel reported significant reductions $(p<0.05)$ in the incidence and duration of diarrhoea. ${ }^{11}$ These findings suggest that prebiotics may be a useful prophylactic strategy for athletes during competition stress and international travel.

Altering GI microbiota through the use of prebiotics may also favourably influence host metabolism, which may also have implications for athletes. Consumption of $16 \mathrm{~g}$ per day of FOS by 10 healthy adults in a randomised, double-blind placebo-controlled trial found that prebiotic consumption reduced appetite and increased plasma gut peptide concentration. ${ }^{12}$ This effect may be of interest for energy-restricted athletes. Another study found that consumption of $23 \mathrm{mg}$ of cocoa flavanols per day for 4 weeks by 22 healthy volunteers reduced the levels of plasma triacylglycerol and the inflammatory marker $\mathrm{C}$-reactive protein. ${ }^{13}$ However, such metabolic effects from supplementation are unlikely to have a direct impact on athletic performance. Whether supplementation may ameliorate exercise-related disturbances, such as gut permeability, immune function, energy balance, or promote recovery, needs to be studied.

In conclusion, prebiotic supplements may be of benefit to athletes by limiting illness impacting on competitive performance. Prebiotics such as GOS and FOS can modify the composition of the GI microbiota and appear to be associated with lower rates of GI and respiratory illness in healthy adults. Although there are no specific studies showing benefits of prebiotics on the health of athletes, there is accumulating evidence from studies of probiotics (see part 31) that alterations in gut microflora can lead to such valuable outcomes. Further research is required in various athlete populations on the various types of prebiotic supplements, dosage, timing (pre-exercise or postexercise) and underlying mechanisms before definitive guidelines on supplementation can be issued.

\section{CONCLUDING COMMENTS}

Potassium plays an important role in muscle function and although leakage of potassium from the cell occurs during exercise, its association with fatigue relates more to body homeostasis rather than to total body loss. There is, of course, some loss of potassium via sweating; however, most athletes will consume adequate amounts of dietary potassium from a wide variety of foods to allow this to be easily replaced. Although potassium is added in small amounts to many electrolyte-replacement supplements including sports drinks, this does not appear to be specifically important. With regard to prebiotics, however, although the evidence for a direct benefit of prebiotic supplementation on athletic performance per se is scant, there is interest in following the story.

Competing interests Nicholas West has been the recipient of commercial funding for research and consultation services from Chr Hansen A/S, Danisco Sweeteners Oy, Probiotec Pharma Pty Ltd.

Provenance and peer review Commissioned; not externally peer reviewed.

\section{REFERENCES}

1. Gropper SS, Smith JL, Groff JL. Potassium. In: Advanced Nutrition and Human Metabolism. Fifth edition. Minneapolis: West Publishing Company 2009:454-455.

2. Devlin TM. Biological membranes: structure, receptors, and solute transport. In: Textbook of Biochemistry. Seventh edition. Hoboken, New Jersey: John Wiley and Sons, Inc 2011:477-479.

3. McKenna MJ. The roles of ionic processes in muscular fatigue during intense exercise. Sports Med 1992;13:134-45.

4. Maughan RJ, Owen JH, Shirreffs SM, et al. Post-exercise rehydration in man: effects of electrolyte addition to ingested fluids. Eur J Appl Physiol Occup Physiol 1994;69:209-15.

5. Shirreffs SM, Armstrong LE, Cheuvront SN. Fluid and electrolyte needs for preparation and recovery from training and competition. J Sports Sci 2004;22:57-63.

6. Bergeron MI. Heat cramps: fluid and electrolyte challenges during tennis in the heat. J Sci Med Sport 2003;6:19-27.

7. Dietary Reference Intakes for Water, Potassium, Sodium, Chloride, and Sulfate. National Academy of Sciences. Institute of Medicine. Food and Nutrition Board, 2004:186-268.

8. Roberfroid M, Gibson GR, Hoyles L, et al. Prebiotic effects: metabolic and health benefits. Br J Nutr 2010;104 (Suppl 2):S1-63.

9. Pyne DB, Hopkins WG, Batterham AM, et al. Characterising the individual performance responses to mild illness in international swimmers. Br J Sports Med 2005;39:752-6.

10. Hughes C, Davoodi-Semiromi Y, Colee JC, et al. Galactooligosaccharide supplementation reduces stress-induced gastrointestinal dysfunction and days of cold or flu: a randomized, double-blind, controlled trial in healthy university students. Am J Clin Nutr 2011;93:1305-11.

11. Drakoularakou A, Tzortzis G, Rastall RA, et al. A double-blind, placebocontrolled, randomized human study assessing the capacity of a novel galactooligosaccharide mixture in reducing travellers' diarrhoea. Eur J Clin Nutr 2010;64:146-52

12. Cani PD, Lecourt E, Dewulf EM, et al. Gut microbiota fermentation of prebiotics increases satietogenic and incretin gut peptide production with consequences for appetite sensation and glucose response after a meal. Am J Clin Nutr 2009;90:1236-43.

13. Tzounis X, Rodriguez-Mateos A, Vulevic J, et al. Prebiotic evaluation of cocoaderived flavanols in healthy humans by using a randomized, controlled, doubleblind, crossover intervention study. Am J Clin Nutr 2011;93:62-72. 


\section{BJSM}

\section{A-Z of nutritional supplements: dietary supplements, sports nutrition foods and ergogenic aids for health and performance --Part 30}

N M DiMarco, N P West, L M Burke, et al.

Br J Sports Med 2012 46: 299-300

doi: 10.1136/bjsports-2012-090933

Updated information and services can be found at:

http://bjsm.bmj.com/content/46/4/299.full.html

\section{These include:}

References This article cites 10 articles, 4 of which can be accessed free at: http://bjsm.bmj.com/content/46/4/299.full.html\#ref-list-1

Email alerting Receive free email alerts when new articles cite this article. Sign up in service the box at the top right corner of the online article.

Notes

To request permissions go to:

http://group.bmj.com/group/rights-licensing/permissions

To order reprints go to:

http://journals.bmj.com/cgi/reprintform

To subscribe to BMJ go to:

http://group.bmj.com/subscribe/ 